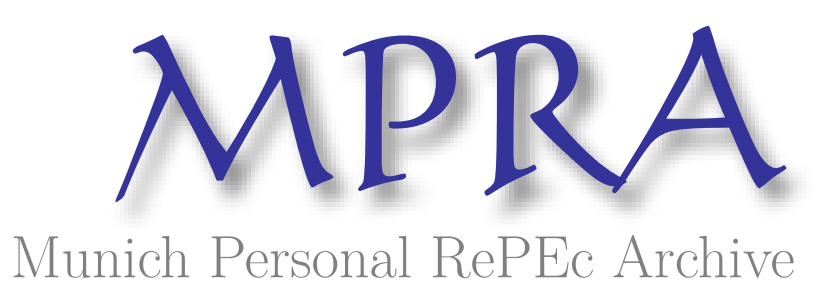

\title{
On-Net/Off-Net Price Discrimination and 'Bill-and-Keep' vs. 'Cost-Based' Regulation of Mobile Termination Rates
}

Harbord, David and Pagnozzi, Marco

January 2008

Online at https://mpra.ub.uni-muenchen.de/14540/

MPRA Paper No. 14540, posted 09 Apr 2009 00:28 UTC 


\title{
On-Net/Off-Net Price Discrimination and 'Bill-and-Keep' vs. 'Cost-Based' Regulation of Mobile Termination Rates*
}

\author{
DAVID HARBORD ${ }^{\dagger}$ \\ MARCO PAGNOZZI ${ }^{\ddagger}$ \\ Market Analysis Ltd \\ Università di Napoli Federico II
}

January 2008

\begin{abstract}
This paper surveys the recent literature on competition between mobile network operators in the presence of call externalities and network effects. It shows that the regulation of mobile termination rates based on "long-run incremental costs" increases networks' strategic incentives to inefficiently set high on-net/off-net price differentials, thus harming smaller networks and new entrants. The paper argues in favor of a "bill-and-keep" system for mobile-to-mobile termination, and presents international evidence in support of this conclusion.
\end{abstract}

*This article is partly based on research undertaken for Hutchison $3 \mathrm{G} \mathrm{UK} \mathrm{Ltd.} \mathrm{The}$ authors, however, are solely responsible for its contents and for the views expressed.

${ }^{\dagger}$ Market Analysis Ltd., 18 Western Road, Grandpont, Oxford OX1 4LG, UK (e-mail: dharbord@market-analysis.co.uk).

†Department of Economics, Università di Napoli Federico II, Via Cintia (Monte S. Angelo), 80126 Napoli, Italy (e-mail: pagnozzi@unina.it). 


\section{Introduction}

The UK telecoms authority (Ofcom) regulates the termination rates of the four incumbent mobile network operators (MNOs) in the UK at "long-run incremental cost" (LRIC), and it has recently included the new entrant, Hutchison 3G UK, within this regulatory framework. ${ }^{1}$ The main rationale for Ofcom's regulation of these charges is to prevent a welfare-reducing distortion in the structure of prices, whereby excessive profits from the exploitation of monopoly power in call termination are used to subsidize subscriber acquisition costs. ${ }^{2}$ Indeed, Ofcom's estimates of the welfare benefits of regulation (Ofcom 2007a, Annex 19, pp. 387-395) are exclusively concerned with correcting this inefficiency in the structure of prices, which it believes leads to over-consumption of mobile retail services and under-consumption of other retail services that use mobile termination, such as fixed retail services (Ofcom 2006, p. 80). ${ }^{3}$

Ofcom treats fixed-to-mobile and mobile-to-mobile termination charges symmetrically, ${ }^{4}$ and its cost model estimates LRIC by allocating the fixed

\footnotetext{
${ }^{1}$ Termination rates are the charges that mobile operators levy on fixed network operators and other mobile operators for terminating calls on their networks. Ofcom (2007a, p. 199) defines "LRIC" as "the additional cost an MNO incurs to provide termination", or "the cost that the firm would avoid if it decided not to provide voice termination, taking a long-run perspective". The price caps for the MNOs in the UK are actually set at Ofcom's estimate of LRIC for each network, plus a markup for common costs and a network externality surcharge.

${ }^{2}$ This issue is frequently discussed in terms of the "waterbed" effect, whereby a reduction (or increase) in termination charges leads to a corresponding increase (or reduction) in subscription charges to consumers (see Ofcom 2006, pp. 77-85; Ofcom 2007a, pp. 101-115; and Armstrong and Wright 2007, pp. 13-14). The characterization of mobile call termination as a "monopoly" assumes that mobile operators can make "take-it-or-leave-it" offers to fixed-line operators and to each other, which is typically justified by reference to various interconnectivity obligations. Binmore and Harbord (2005) question this assumption, and provide an analysis of mobile call termination instead as a bilateral-monopoly bargaining problem.

${ }^{3}$ That is, Ofcom does not claim that the MNOs in the UK are earning excessive profits overall via excessive charges for voice termination (see Ofcom 2007a, pp. 8-9), although it "remains of the view that the waterbed effect is unlikely to be complete" (Ofcom 2007a, p. 109). See Genakos and Valletti (2007) for recent empirical evidence on the strength of the waterbed effect in twenty countries.

${ }^{4}$ Specifically, the price caps, or "target average charges," for the two services are set at
} 
and common costs of a hypothetical efficient network operator over mobile retail and wholesale services. ${ }^{5}$ We shall argue in this paper that this approach to regulating termination charges is flawed for a number of reasons, and that consequently Ofcom's regulatory policy — by distorting retail pricing incentives in the mobile market - may be doing as much harm as good.

A first simple point, which has been frequently made elsewhere ${ }^{6}$ is that even in the absence of any strategic effects (which are discussed immediately below), the regulation of pence per minute (ppm) mobile termination charges should in principle be based on marginal costs, and not on the fully-allocated costs estimated by Ofcom's LRIC model. Very few, if any, mobile telecommunications costs are traffic-sensitive, but they are nevertheless recovered on a traffic-sensitive basis under Ofcom's approach. To the extent that regulated termination rates represent fixed costs that are recovered on a per-minute basis, they are too high, and act to inefficiently increase retail call charges and reduce the number of calls made to mobile networks.

Ofcom is therefore allowing MNOs in the UK to charge termination rates which are likely to be far in excess of marginal costs. ${ }^{7}$ A more efficient price structure would set per-minute rates at or near zero, but possibly allow for networks to contribute to each others' capacity costs via capacity surcharges. If, for most practical purposes, such capacity charges can be expected to net out, a better regulatory policy is likely to be "bill-and-keep," under which

the same level. See Ofcom (2007a, pp.404-408).

${ }^{5}$ See Ofcom (2007a), Annex 5, especially paragraphs 5.11-5.19.

${ }^{6}$ See, for example, Quigley and Vogelsang (2003) and DeGraba (2003).

${ }^{7}$ Some compelling evidence for this comes from the fact that MNOs in the UK and Europe frequently set prices for on-net calls - i.e. calls originating and terminating on their own networks - much lower than regulatory estimates of their incremental termination costs. For example, Ofcom's estimates of LRIC for the incumbent UK operators in 2006 all exceeded $5 \mathrm{ppm}$, whereas the average price of on-net calls in 2006 was reported to be 3.5 ppm (Ofcom 2007b, Figure 4.40). Similarly, the Portuguese regulator (ANACOM 2007) has recently estimated that on this basis, termination costs in Portugal are of the order of $€ 0.036$ per minute, compared to the regulated rate of $€ 0.11$ per minute. See also the discussion of the French regulator ARCEP (2007), Chapter 4 and pp. 81-82. 
reciprocal termination charges are set equal to zero. ${ }^{8,9}$

Our second point is more complex, and has only recently become clear as the academic literature on network competition has become increasingly realistic. It now appears that Ofcom's regulatory policy is founded on an incomplete understanding of competitive interaction in mobile markets, which has led it to focus on one potential distortion in relative prices at the expense of others. Its LRIC-based price regulation is consequently contributing to another welfare-reducing distortion of prices - off-net versus on-net price discrimination - which is particularly damaging to new entrants and to competition from smaller networks. By focusing solely on the absolute level of mobile termination rates, and associated "waterbed" effects, Ofcom's regulatory policy may well be damaging competition and reducing welfare in the mobile market.

It is now widely recognized that new entrants in mobile markets face a barrier to entry due to the structure of prices charged by incumbent networks. In particular, on-net versus off-net price differentials create tariff-mediated network externalities, as described by Laffont et al. (1998b), which make larger networks more attractive to consumers than smaller networks. When on-net calls are priced below off-net calls, ceteris paribus, subscribers to large networks experience lower average call charges than subscribers to smaller networks, since more of their calls are made on-net. This makes larger networks more attractive and places smaller networks at a competitive disadvantage.

Large price differentials for on-net and off-net calls are common in most European mobile markets. In the UK, according to Ofcom's own estimates, the average charge in 2002 was 22.6 ppm for off-net calls versus 5.1 ppm for

\footnotetext{
${ }^{8}$ Quigley and Vogelsang (2003), for example, argue that, "capacity-based interconnection charges would be ideal, because they would correctly reflect the costs incurred by the networks," and note that, "bill and keep is like a two-part tariff in access charges: the fixed fee equals the own-network costs for termination of the call generated by the other network, while the variable fee is zero."

${ }^{9}$ Armstrong and Wright (2007, p. 14) suggest another reason for excluding fixed and common costs from regulated termination charges in competitive mobile markets. In the presence of strong "waterbed" effects, high termination charges will not provide MNOs with any contribution towards their fixed or common costs, but rather be dissipated in competition to attract new subscribers.
} 
on-net calls. Although by 2006 this differential had been reduced to $8.9 \mathrm{ppm}$ for off-net calls versus 3.5 ppm for on-net calls, it remains significant. ${ }^{10}$ Data from European countries such as France, Germany and Spain tell a similar story. $^{11}$

If networks have roughly equal termination costs, however, economic efficiency requires equal on-net and off-net call charges. So why do mobile operators set large price differentials for on-net and off-net calls? ${ }^{12}$ This issue has recently been addressed in a number of recent papers, including Jeon et al. (2004), Berger (2004) (2005), Armstrong and Wright (2007), Hoernig (2007), and Calzada and Valletti (2007), who consider the impact of call externalities and network effects on competition and market structure in the mobile sector. Call externalities refer to the fact that both the sender and receiver of a call receive a benefit from it, although under a "Calling Party Pays" (CPP) regime only one party is charged for the call. The importance of call externalities is beyond doubt, but they have been largely ignored until recently both by the academic literature and by regulatory authorities. DeGraba (2000, p. 15), for example, notes that:

"the economic analyses of interconnection pricing generally assumed that the calling party is the sole cost-causer and the sole beneficiary of a call. While these assumptions may have been a useful means of simplifying the analysis of various interconnection pricing problems, they have long been recognized as unreal-

\footnotetext{
${ }^{10}$ See Figure 4.40 in Ofcom (2007b).

${ }^{11}$ See Section 4.2 below for further detail; also Armstrong and Wright (2007, pp. 6-7). As Armstrong and Wright note, it is a complex and largely arbitrary task to give precise estimates for the prices of the various types of calls and messages originating on mobile networks, since mobile networks each offer a wide variety of tariffs, with different monthly rentals, corresponding to different volumes of inclusive call minutes and text messages. The method of calculation used by Ofcom is not made clear in their documents.

${ }^{12}$ The academic literature was until recently unable to explain on-net/off-net price discrimination. This literature — like Ofcom - focused on the exploitation of monopoly power in setting termination rates to subsidize competition to acquire subscribers. It also concluded that purely cost-based access (i.e. termination) charges are welfare optimal, and that consequently fixed-to-mobile and mobile-to-mobile termination charges should be regulated at the same level. See, for example, Armstrong (2002); Wright (2002a); and Gans and King (2000a).
} 
istic, and, with the growth of competition in telecommunications, they need to be reconsidered."

The inclusion of call externalities in the analysis is of particular importance, since this has been shown to have significant effects on competition, the structure of retail prices, and optimal regulatory policy. The main conclusion of the more recent literature is that, in the presence of call externalities, mobile networks have strong incentives to implement on-net/off-net price differentials due to: (i) high mobile-to-mobile termination charges which exceed marginal cost; and (ii) their strategic incentives to reduce the number of calls that subscribers on rival networks receive, reducing the attractiveness of rival networks, and hence their ability to compete. This literature also finds that:

- large networks charge higher off-net prices, and create higher on-net/offnet price differentials, than smaller networks. This reduces the attractiveness of smaller networks, since subscribers to a large network can be expected to make proportionately more on-net calls than the customers of a smaller network. Ceteris paribus, subscribers to smaller networks will experience higher average call charges, placing the smaller network at a competitive disadvantage;

- high (i.e. above marginal cost) mobile-to-mobile termination charges can lead to permanent "access deficits" for smaller networks, because even with a "balanced calling pattern" 13 traffic between networks will not be in balance. Call externalities reinforce this effect, since when large networks set high off-net prices, subscribers of a smaller network will also receive relatively few calls; and

- welfare-optimal termination charges should be below the marginal costs of termination for both fixed-to-mobile and mobile-to-mobile calls, in order to reduce incentives for on-net/off-net price discrimination. But optimal mobile-to-mobile termination charges will typically be lower than fixed-to-mobile termination charges to take account of the fact

\footnotetext{
${ }^{13}$ Where in the absence of tariff differentials, each subscriber calls every other subscriber with the same probability.
} 
that the retail prices of mobile-to-mobile calls are unregulated, and the greater intensity of competition between mobile networks than between fixed versus mobile networks.

Thus, Ofcom's policy of imposing identical "cost-based" rates for fixedto-mobile and mobile-to-mobile calls is unlikely to be optimal, even if we assume that its LRIC model provides reasonable estimates of the marginal costs of termination, since both rates should be less than marginal cost, and by different amounts. In any event, as noted above, Ofcom's methodology results in termination charges which are evidently far in excess of marginal termination costs.

"Cost-based" regulation of termination rates is consequently exacerbating the incentives of MNOs to set off-net prices in excess of on-net prices, resulting in welfare losses from an inefficient pricing structure and barriers to entry and growth for smaller networks. Indeed, it is plausible that high off-net call charges are a distortion in the structure of prices potentially as serious as the distortion in prices that the regulation of mobile termination charges was designed to repair in the first place (i.e. the subsidy of mobile subscription via high termination charges), and are particularly damaging to competition from smaller networks and new entrants.

A move to "bill-and-keep" for mobile-to-mobile termination — as suggested by Berger (2004) (2005), DeGraba (2003) (2004), Littlechild (2006), Quigley and Vogelsang (2003) and Valetti and Houpis (2005) — would likely result in a more efficient wholesale and retail price structure, help to eliminate barriers to entry caused by "tariff-mediated" network effects, and increase welfare and competition in the mobile market. While Gans and King (2001) argued that bill-and-keep arrangements can be used to soften retail competition between mobile networks, and may hence be undesirable, the more recent literature has shown that when call externalities are taken into account, this conclusion changes. Indeed, when both parties to a call receive benefits from it, setting access charges equal to the cost of completing a call is typically inefficient, and bill-and-keep, by imposing some of the cost of a call on each network, is more efficient than cost-based termination charges. ${ }^{14}$

\footnotetext{
${ }^{14}$ And as we note in Section 3 below, bill-and-keep can be more efficient than cost-based
} 
Recent empirical evidence (e.g. Birke and Swann 2006, 2007) confirms that tariff-mediated network effects play an important role in mobile telecommunications, and that inducing network effects via off-net/on-net price differentials has been a successful strategy for incumbent mobile operators in Europe. According to Birke and Swann (2006), their empirical analysis supports the conclusion that, "the high price of off-net calls cannot only be a result of market power, but can be a significant source of market power, which can especially be used to preempt entry by new competitors." These studies thus provide support for the recent theoretical literature which suggests that strategically inducing network effects can be a profitable strategy for attracting and maintaining market share, and for preempting entry or retarding the growth of smaller networks. International evidence from countries where bill-and-keep has been used in practice also appears to support the conclusion that bill-and-keep arrangements tend to encourage a more efficient retail pricing structure.

The remainder of this survey paper is organized as follows. Section 2 describes the recent academic literature on call externalities and competition between mobile networks, leading to the conclusions noted above, while Section 3 considers the theoretical arguments for and against bill-and-keep as a basis for setting termination charges. Section 4 then discusses some empirical evidence. Section 4.1 describes the recent results of Birke and Swann (2006)(2007), who attempt to quantify the extent of off-net/on-net price discrimination in the UK and other countries, and its effects on consumers' subscription behavior. Section 4.2 describes some international evidence on prices, usage and penetration levels in bill and keep countries compared to countries with relatively high termination rates. Section 5 concludes.

termination charges even when traffic between networks is not in balance, contradicting the widely-held view that bill-and-keep arrangements are only appropriate when traffic between networks is balanced. 


\section{Call Externalities and Competition Between Networks}

As noted above, the academic literature on network competition was until recently unable to explain the large price differentials for on-net and off-net calls observed in most European mobile markets. The standard conclusions were that purely cost-based access (i.e. termination) charges were welfare optimal, and that consequently fixed-to-mobile and mobile-to-mobile termination charges should be regulated at the same level.

These conclusions have now been overturned in a number of recent papers which consider the effects of call externalities and network effects on competition and pricing in mobile markets. The inclusion of call externalities in the analysis has been found to have significant implications for welfare and optimal regulatory policy. As Armstrong and Wright (2007) have noted, "it is beyond doubt that call externalities are significant, since why else would anyone leave their mobile phone on to receive calls?" What wasn't clear until recently was the significance of call externalities for the analysis of price discrimination and competitive interaction in mobile markets.

This section summarizes the results of a number of recent papers which analyze the interaction of call externalities with pricing and competition in mobile networks, including Jeon et al. (2004), Armstrong and Wright (2007), Hoernig (2007), Calzada and Valletti (2007), and Cambini and Valletti (2007). The key conclusions of this analysis are that call externalities create a strategic motive for off-net/on-net price discrimination which can lead to socially inefficient tariff structures, and create an entry barrier for small networks which are unable to profitably replicate incumbents' pricing strategies. Further, high mobile-to-mobile termination rates, coupled with high charges for off-net calls, can be used strategically by incumbent operators to either prevent entry or reduce competition from new entrants into their markets.

Jeon, Laffont and Tirole (2004) Jeon et al. (2004) analyze competition between two symmetric communications networks which compete in nonlinear prices, and in which both senders and receivers of calls benefit from them 
- i.e. in the presence of call externalities. Specifically, they assume that a sender obtains a gross surplus $u(q)$ from a call of length $q$, while the receiver obtains a surplus of $\widetilde{u}(q)=\beta u(q)$, where $\beta>0$ is a measure of the strength of the call externality. Each network $i$ charges its subscribers a fixed fee $F_{i}$, and per-unit call charges $p_{i i}^{*}$ for on-net calls and $p_{i j}^{*}$ for off-net calls, for $i, j=1,2$.

Jeon et al. (2004) show that, with "network-based price discrimination" (i.e. when firms are allowed to set different prices for on-net and off-net calls), each firm fully internalizes the call externalities on its own network, and sets an on-net price equal to marginal cost less a factor which depends upon the size of the call externality. By contrast, because off-net call charges affect the welfare of consumers on the rival network, they are subject to strategic manipulation.

Specifically, when $c_{O}$ is the marginal cost of originating a call and $c_{T}$ is the marginal cost of terminating a call, the profit-maximizing on-net price for network $i$ is equal to the social-welfare-maximizing price,

$$
p_{i i}^{*}=c_{O}+c_{T}-\widetilde{u}^{\prime}\left(q\left(p_{i i}^{*}\right)\right) .
$$

Since each firm has a monopoly in the market for on-net calls on its own network, it uses the efficient on-net call price $p_{i i}^{*}$ to maximize the total surplus, and the fixed charge $F_{i}$ to extract consumer surplus. Hence, both networks choose the same on-net price regardless of their market shares, and on-net calls are priced below total marginal cost.

Noting that in equilibrium $\widetilde{u}^{\prime}\left(q\left(p_{i i}^{*}\right)\right)=\beta p_{i i}^{*}$, equation (1) may be rewritten as

$$
p_{i i}^{*}=\frac{c_{O}+c_{T}}{1+\beta} .
$$

Thus in the absence of a call externality (i.e. when $\beta=0$ ), on-net prices for each network are set equal to marginal cost, and always exceed zero for any finite value of $\beta$.

By contrast, given that network $i$ has market share $\alpha_{i}$, the profit-maximizing 
off-net price for network $i$ is given by ${ }^{15}$

$$
p_{i j}^{*}= \begin{cases}\frac{\left(1-\alpha_{i}\right)\left(c_{0}+a\right)}{1-\alpha_{i}(1+\beta)} & \text { for } \alpha_{i}<\frac{1}{1+\beta}, \\ +\infty & \text { otherwise, }\end{cases}
$$

where $a$ is the reciprocal mobile-to-mobile termination access charge, which is assumed to be equal for the two networks. Note that from $(3), \frac{\partial p_{i j}^{*}}{\partial \alpha_{i}}>0 .{ }^{16}$ Hence a larger network charges a higher off-net price, and has a higher offnet/on-net price differential, than a smaller network.

In a symmetric equilibrium, when $\alpha_{i}=\alpha_{j}=\frac{1}{2}$, the profit-maximizing off-net price is given by

$$
p_{i j}^{*}= \begin{cases}\frac{c_{0}+a}{1-\beta} & \text { for } 0 \leq \beta<1, \\ +\infty & \text { for } \beta \geq 1\end{cases}
$$

for each network. In the absence of a call externality (when $\beta=0$ ), the offnet price is equal to $c_{O}+a$ and the on-net price to $c_{O}+c_{T}$ : the on-net/off-net price differential is therefore completely determined by $a-c_{T}$, the difference between marginal termination costs and the termination access charge. ${ }^{17}$

When the call externality is taken into account, however, strategic considerations change this result. The call externality creates strong incentives for each firm to increase its off-net price in order to reduce the number of calls made to the rival network, thereby reducing the attractiveness of the rival network to subscribers. Further, when the receiver of a call benefits as much as, or more than, the sender (i.e. when $\beta \geq 1$ ), this leads to what Jeon et al. (2004) refer to as a "connectivity breakdown," where both networks set off-net call charges so high as to eliminate off-net calling altogether. Intuitively, a network's profitability is determined by the attractiveness of its

\footnotetext{
${ }^{15}$ Equation (3) is obtained by maximizing network $i$ 's profit with respect to $p_{i j}$ for a given market share, adjusting the fixed charge to keep its market share constant when it changes its off-net price, and then using the fact that $p_{i j}^{*}=u^{\prime}\left(q\left(p_{i j}^{*}\right)\right)$ to obtain the equilibrium price.

${ }^{16}$ Specifically, $\frac{\partial p_{i j}^{*}}{\partial \alpha_{i}}=\frac{\left(c_{0}+a\right) \beta}{\left[1-\alpha_{i}(1+\beta)\right]^{2}}$.

${ }^{17}$ De Bijl and Peitz (2002, ch. 6.4) also solve for the equilibrium pricing structure with two-part tariffs and price discrimination in the absence of a call externality. As in Jeon et al. (2004), both on-net and off-net prices are set equal to marginal cost, and therefore the on-net/off-net price differential is completely determined by the reciprocal termination charge.
} 
offer relative to that of its competitor. By allowing off-net calls, a network bears the cost of those calls and, if the receivers enjoy a sufficiently high surplus from receiving calls, this makes the other network relatively more attractive. $^{18}$

In less drastic cases, when $\beta<1$, competition for market share leads to "suboptimal connectivity." That is, off-net prices which result in too few off-net calls being made relative to the welfare optimum. This can be seen from the fact that the social-welfare-maximizing off-net price is equal to the on-net price in equation (1). From (4), two factors potentially increase the firms' off-net prices above the first-best value: the access charge $a$, and the call externality effect represented by $\beta$. Comparing equations (2) and (4) it is clear that, even when the reciprocal termination charge $a$ is set equal to marginal $\operatorname{cost} c_{T}$, equilibrium off-net call charges still exceed the efficient level due to the strategic effect induced by the presence of the call externality. ${ }^{19}$

Armstrong and Wright (2007) Armstrong and Wright (2007, Section 3) use a similar set-up to that of Jeon et al. (2004), ${ }^{20}$ to analyze pricing and termination charges in an oligopolistic market which includes both mobile and fixed networks. In contrast to Jeon et al. (2004), however, they assume that the receiver of a mobile-to-mobile call of length $q$ obtains a surplus $b \cdot q$, where $b>0$ is the measure of the strength of the mobile-to-mobile call externality; and the receiver of a fixed-to-mobile call of length $q$ obtains a surplus $B \cdot q$, where $B>0$ is the measure of the strength of the fixedto-mobile call externality. Therefore, Armstrong and Wright (2007) restrict the analysis to linear call externalities which are unrelated to the surplus obtained by the caller. ${ }^{21}$

\footnotetext{
${ }^{18}$ This result requires that the market is "covered" — i.e. that every consumer subscribes to a network.

${ }^{19}$ This can also be seen by noting that $\frac{\partial p_{i j}^{*}}{\partial a}=\frac{1}{1-\beta}>1$ when $\beta>0$ in (4), so an increase in the reciprocal termination charge results in an increase in both networks' off-net prices which exceed the increase in the termination charge.

${ }^{20}$ Both papers build on the model in section 8 of Laffont, Rey, and Tirole (1998a).

${ }^{21}$ One way of understanding this distinction is to note that Jeon et al. (2004) assume that the "total surplus" from a call, $(1+\beta) u(q)$, is "shared" by the sender and receiver in proportions $\frac{1}{1+\beta}$ and $\frac{\beta}{1+\beta}$ respectively. Armstrong and Wright (2007), on the other hand, treat the sender's utility as being completely urelated to the benefit obtained by the
} 
The welfare-maximizing fixed-to-mobile call price in the set-up of Armstrong and Wright (2007) is given by

$$
P^{*}=C+c_{T}-B
$$

where $C$ is the marginal origination cost of the fixed network. That is, the fixed-to-mobile price should equal the total marginal cost of a fixed-tomobile call less the relevant call externality. As in Jeon at al. (2004), the profit-maximizing on-net price for network $i$ is equal to the social-welfaremaximizing call price, which is given here by

$$
p_{i i}^{*}=c_{O}+c_{T}-b,
$$

or the mobile network's on-net marginal cost adjusted downwards to reflect the call externality its subscribers enjoy from being called by people on the same network.

By contrast, in a symmetric equilibrium, each mobile firm sets its profitmaximizing off-net price equal to

$$
p_{i j}^{*}=c_{O}+a+\frac{1}{n-1} b
$$

where $a$ is again the reciprocal termination charge, and $n$ is the number of mobile firms. This exceeds the welfare-maximizing price given by equation (6), and is equal to a network's marginal cost for an off-net call adjusted upwards to reflect the fact that when a network's subscribers make fewer calls to subscribers of other networks, the utility of subscribers to other networks is reduced because of the call externality. As Armstrong and Wright (2007, p. 18) note, "this represents the chief anti-competitive motive to set high off-net call charges."

Although the qualitative effect of call externalities on the networks' mobileto-mobile prices is the same as in Jeon et al. (2004), because of the different assumptions on the nature of the call externality the model of Armstrong and Wright (2007) never leads to infinite off-net mobile-to-mobile prices and "connectivity breakdown." ${ }^{22}$ As in Jeon et al. (2004), however, setting the receiver.

${ }^{22}$ Although for a large enough externality parameter, $b$, it can predict negative on-net prices. 
reciprocal mobile-to-mobile termination charge equal to marginal cost, i.e. $a=c_{T}$, does not lead to efficient off-net prices, and does not eliminate onnet/off-net price differentials.

Both models thus predict that the observed differences in on-net and off-net call charges are not solely due to mobile-to-mobile termination rates which exceed marginal cost . Rather, networks set high off-net prices in order to reduce the number of calls received by subscribers on rival networks, thus reducing the rival networks' ability to compete. ${ }^{23}$ Mobile-to-mobile off-net prices are distorted away from their welfare-maximizing levels by both the regulated mobile-to-mobile termination rate $a$, and by the "strategic effect," which in the model of Armstrong and Wright (2007) is represented by the term $\frac{1}{n-1} b$ in equation (7).

When the prices of fixed-to-mobile calls are regulated at cost (so that $P=C+A$ ), as they have been until recently in the UK for example, from (5) the optimal fixed-to-mobile termination charge in Armstrong and Wright's model is given by

$$
A^{*}=c_{T}-B
$$

i.e. the mobile networks' marginal cost of termination less the fixed-to-mobile call externality. In the absence of regulation, but assuming that fixed networks and mobile networks are not viewed as substitutes for each other by consumers, the optimal fixed-to-mobile access charge is still given by (8). This is because, when fixed and mobile networks are not substitutes, fixed networks have no strategic motive for setting fixed-to-mobile call prices above marginal cost, so long as they are able to extract consumer surplus via fixed fees. ${ }^{24}$ Hence, setting the fixed-to-mobile access charge according to (8) is

\footnotetext{
${ }^{23}$ See Armstrong and Wright (2007, pp. 18-19) for a discussion.

${ }^{24}$ Using world data on mobile penetration rates, Gruber and Verboven (2001a) and Anh and Lee (1999) find that fixed and mobile telephony are largely viewed as complements by consumers. In contrast, using penetration data for the European Union from 1991-1997, Gruber and Verboven (2001b) find a substitution effect between fixed and mobile phones. Cadima and Barros (2000) and Sung and Lee (2002) report analogous results using data from Portugal and Korea respectively. Gans, King and Wright (2005) hypothesize that the conflicting results may be due to the fact that fixed and mobile phones were initially complements, but as mobile penetration has increased, they are increasingly being viewed as substitutes. See also Andersson et al. (2006).
} 
likely to be approximately optimal even in the absence of regulation of fixedto-mobile retail prices.

The welfare-maximizing mobile-to-mobile termination rate, which sets off-net charges equal to on-net charges (i.e. $p_{i j}^{*}=p_{i i}^{*}$ ), is given by

$$
a^{*}=c_{T}-\frac{n}{n-1} b .
$$

Hence, when $B=b$, the welfare-maximizing fixed-to-mobile termination rate $A^{*}$ exceeds the welfare-maximizing mobile-to-mobile rate $a^{*}$, and only as $n$ becomes large does this difference vanish. ${ }^{25}$ Welfare-maximizing mobile-tomobile access charges need to be lower than fixed-to-mobile access charges to off-set the strategic motive for setting mobile-to-mobile off-net charges which are too high relative to their first best levels, and these strategic motives are largely absent for fixed network firms.

As in Berger (2005) and Gans and King (2000b), Armstrong and Wright (2007) also show that, if mobile networks are able to coordinate on reciprocal termination charges, they will choose a mobile-to-mobile termination rate below marginal cost, in order to relax competition for subscribers. The reason is that, from equation (7), a higher termination charge makes off-net calls more expensive than on-net calls, and the mobile market then exhibits positive network effects, in the sense that subscribers will prefer to join a larger network. This intensifies competition between networks for market share, and reduces profits. Agreement on a low reciprocal termination charge results in off-net prices which are below on-net prices, so subscribers will prefer to join a smaller network, which relaxes retail-market competition. ${ }^{26}$

Armstrong and Wright (2007, pp. 16-17), however, note an anti-competitive motive for large networks to prefer high termination charges when facing the threat of entry by smaller networks, vis. that "high mobile-to-mobile

\footnotetext{
${ }^{25}$ It is not easy to think of a good reason for the call externality parmeters to be different for the two types of network. Hence, $B=b$ appears to be a reasonable assumption.

${ }^{26}$ The prediction that mobile networks should agree on low mobile-to-mobile termination charges contrasts sharply with what these firms actually do in practice, however, casting considerable doubt on the ability of mobile networks to coordinate on profit-maximizing termination rates. As Armstrong and Wright (2007, p. 20) put it, "it is by no means clear that unregulated networks do actually negotiate over their mutual MTM termination charges."
} 
termination charges may deter entry." By setting mobile-to-mobile termination rates above cost, incumbent mobile networks can induce network effects which make entry less attractive for newcomers. In particular, high termination rates result in higher prices for off-net calls, which harms smaller networks since most of their subscribers' calls will be made off-net. Call externalities reinforce this effect: when the incumbent networks set high off-net prices, subscribers of smaller networks will receive relatively few calls, thus reducing the utility from joining a smaller network. This is a theme which has been taken up by Hoernig (2007) and Calzada and Valletti (2007).

Hoernig (2007) The argument that high off-net prices can be used to create network effects which reduce the competitive threat posed by smaller networks is developed in Hoernig (2007), who analyzes the duopoly model of Jeon et al. (2004) with asymmetrically-sized networks. He assumes that the termination charge is set by the regulator, and analyzes Nash equilibria with price discrimination between on-net and off-net calls, for both linear and twopart tariffs. He also considers the possibility that the larger network engages in a form of "predatory pricing," whereby it leverages the tariff-mediated network externality to reduce the profits of the smaller network.

Hoernig (2007) finds that both asymmetries in network size and call externalities have strong effects on the equilibrium on-net and off-net prices, and the resulting price differentials. Specifically, the large network charges higher off-net prices, and creates a higher on-net/off-net differential, than the smaller network, in order to improve its relative competitive position by making the rival network less attractive. This result can be readily obtained from equations (2) and (3) above. ${ }^{27}$

As a result, even with a "balanced calling pattern" - i.e. when each consumer calls every other consumer with the same probability in the absence of any tariff differentials — the traffic between the two networks will

\footnotetext{
${ }^{27}$ One way of explaining this is that with call externalities, an increase in a network's offnet price has a first-order effect on the attractiveness of the rival network for subscribers. This effect is greater for larger networks, because larger networks have more subscribers who call the subscribers of the other network and generate a call externality for them. In other words, with call externalities, receiving calls from the other network is relatively more important for the smaller network's subscribers.
} 
not be in balance, because the number or the duration of calls is affected by the different prices charged by the two networks. Therefore, when the reciprocal access charge is above marginal cost, the smaller network will incur a permanent access deficit due to its lower off-net price. Hoernig (2007) shows that this result holds under both linear and two-part tariffs. With linear tariffs the larger network also charges a higher on-net price, while with two-part tariffs both firms set the on-net price at the socially efficient (and profit-maximizing) level.

But Hoernig (2007) argues that a large network is capable of further harming the small network by adopting an anti-competitive, predatory-pricing strategy aimed at inducing the smaller network to exit the market. By increasing its off-net price above the Nash equilibrium level, the large network can further reduce the smaller network's access revenue (if access is priced above cost), and the call externality enjoyed by the small network's customers.

Hoernig considers both "full predation" which, by choosing arbitrarily low on-net prices and high off-net prices, allows the large network to drive the market share and profits of the smaller network to zero; and "limited predation," which instead of provoking immediate exit restricts the small firm's profits and cash flows, making it more difficult for it to invest in either customer retention or improvement of its network.

In either case, predation involves a larger on-net/off-net price differential by the large network. As the author stresses, call externalities are crucial for this result. In the absence of a call externality, the on-net/off-net differential is driven by the access charge. By contrast, in the presence of the call externality, this differential is also driven by the difference in market shares between networks and by strategic motivations. ${ }^{28}$

Calzada and Valletti (2007) While Hoernig (2007) assumes that termination charges are set by the regulator, Calzada and Valletti (2007) consider whether networks can strategically coordinate on reciprocal access charges

\footnotetext{
${ }^{28}$ Another way of saying this is that in the absence of call externalities, high off-net prices on the larger network have no effect on the utility of subscribers to the smaller network, by definition, since these subscribers do not care about receiving calls.
} 
in order to reduce competition and entry in their market. They consider a multi-firm industry in which the incumbent networks negotiate termination rates which apply to all firms, including new entrants, and allow for network-based price discrimination. Since the firms' profits are not neutral with respect to the industry-wide termination charge, the incumbent operators recognize that the level of the access charge affects ex post profitability, and thus the attractiveness of entry ex ante. Calzada and Valletti (2007) identify circumstances in which incumbents will want to distort access charges away from the efficient level in order to deter the entry of potential rivals. For a given fixed cost of entry, incumbent firms may decide to accommodate entry, accommodate only a subset of entrants, or deter entry altogether.

As observed by Armstrong and Wright (2007) (discussed immediately above), Calzada and Valletti (2007) show that when the incumbents do not face entry threats, they will agree on below-cost termination rates. Under the threat of entry, however, the incumbent networks may choose to set an inefficiently high access charge which deters the entry of potential rivals into the industry. The reason, as noted, is that a high access charge reduces the entrant's profits ex post, reducing the attractiveness of entry into the market. Calzada and Valletti (2007) note that, "whenever incumbents increase the access charge above cost in order to deter entrants, they introduce allocative distortions for calls, as the off-net price is set above marginal cost. This behaviour also limits the gains from entry for consumers."

Call externalities - which Calzada and Valletti model by assuming that groups of people that tend to call each other more often join the same network - further increase incumbents' incentives to coordinate on a high access charge in order to deter entry. The reason is that a high access charge makes it less attractive for an incumbent network's subscribers to join an entrant network, because doing so means that a larger fraction of their calls will be made off-net. Call externalities of this type imply that the entrant suffers more from any mark-up of the access price, while the incumbents suffer less. ${ }^{29}$

\footnotetext{
${ }^{29}$ Atiyah and Dogan (2006) (see also Calzada and Valletti 2007, pp. 2-3), discuss the example of the Turkish mobile industry, where the incumbent duopolists (Turkcell and Telsmin) agreed to low reciprocal access charges until March 2001, but then they sharply increased their termination rates from 1.5 eurocents $/ \mathrm{min}$ to 20 eurocents $/ \mathrm{min}$, when faced with the prospect of entry by two new operators (Aria and Ayacell). After struggling to
} 
Internalizing Call Externalities? Despite their prominence in the recent theoretical literature, call externalities have been largely ignored by European regulatory authorities to date. ${ }^{30}$ During the last Competition Commission inquiry in the UK, Ofcom suggested that call externalities did not justify any adjustment to termination charges because

"it was possible that call externalities were already largely internalized as people tended to be in stable calling relationships with each other. The caller might be prepared to make a call even if his expected benefit was less than the price, because he expected that a further call (or calls) would be generated, initiated and paid for by the other party, from which he would receive a benefit without having to pay." 31

The empirical basis for these assertions is unclear, however. In any event, the strategic incentive to engage in off-net/on-net price discrimination discussed above depends primarily upon the existence of receiver benefits from receiving calls, which is not in dispute, and less upon the degree to which the associated externalities may be internalized by people in stable calling relationships. Therefore, even if call externalities are partially or fully internalized, to the extent that a call to a subscriber on a rival network benefits the receiver, a network still has a strategic incentive to set inefficiently high

reach profitability, the two new operators merged to form Avea in 2003, resulting in a market structure with only three operators.

${ }^{30} \mathrm{~A}$ notable exception is the Portuguese regulator, ANACOM, that has recently implicitly recognized their effects in referring to the "strong network effects" which create a competitive disadvantage for the smaller network, Optimus, in the Portuguese mobile market. It further argued that these network effects were being intensified by the large networks' on-net/off-net price differentiation. See Case PT/2007/0707: "Remedies related to the market for voice call termination on individual mobile networks in Portugal: Comments pursuant to Article 7(3) of Directive 2002/21/EC1."

${ }^{31}$ Competition Commission (2003), paras. 8.257 to 8.260. See also Ofcom, Statement on Wholesale Mobile Voice Call Termination, 2003, D.16, where it states: "Call externalities - while they almost certainly do exist - probably do not justify any adjustment to call prices. As noted in Oftel's Review of the Charge Control on Calls to Mobiles (2001), and in the CC report, these are likely to be effectively internalised by callers, as a high percentage of calls are from known parties and there are likely to be implicit or explicit agreements to split the origination of calls." 
off-net prices to reduce the number of calls received by rival networks' subscribers.

This can be seen in the recent analysis of Cambini and Valetti (2007), who consider a model of "call propagation" in which each outgoing off-net call results in a fraction $x$ of incoming calls. Comparing their results with Jeon et al. (2004), the authors show that networks will have reduced incentives to use off-net/on-net price discrimination to induce a connectivity breakdown when outgoing and incoming calls are complements, but that off-net/on-net price differentials do not disappear.

Specifically, Cambini and Valetti (2007) find that the profit-maximizing off-net price is equal to

$$
p_{i j}^{*}=\frac{c_{0}+a-\left(a-c_{T}\right) x}{1-\beta(1-x)},
$$

which takes finite values for $0 \leq \beta \leq \frac{1}{1-x}$. This is lower than the off-net price obtained by Jeon et al. (2004) (see equation (4) above), showing that call propagation does reduce a network's incentive to set high off-net prices. Note, however, that even if the termination rate is set equal to marginal cost (i.e. $a=c_{T}$ ), the strategic incentive to inefficiently increase the off-net price above marginal costs remains, since equation (10) is higher than $c_{O}+c_{T}$ as long as $x<1$ (which is the empirically relevant case). ${ }^{32}$

Call propagation, in any event, is not identical to the notion of "internalizing call externalities." 33 Suppose instead that individuals in stable calling relationships fully internalized the call externality, as hypothesized by Ofcom's quote above, and consider the model of Jeon et al. (2004). Then the sender of a call acts so as to maximize the total utility of the call, which is given by $(1+\beta) u(q)$ when call externalities are fully internalized, and so sets $p_{i j}^{*}=(1+\beta) u^{\prime}\left(q\left(p_{i j}^{*}\right)\right)$.

\footnotetext{
${ }^{32}$ Cambini and Valletti (2007) cite the empirical evidence in Taylor (2004), who in turn cites the point-to-point demand models of Southwestern Bell and Telecom Canada, which suggest that "a call in one direction stimulates something like one-half to two-thirds of a call in return."

${ }^{33}$ Taylor (2004, Section 3) sharply distingushes call externalities from what he terms "the dynamics of information exchange."
} 
It is straightforward to show that, in this case, the equilibrium off-net price for a network $i$ with market share $\alpha_{i}$ is then given by ${ }^{34}$

$$
p_{i j}^{*}= \begin{cases}\frac{\left(1-\alpha_{i}\right)\left(c_{0}+a\right)}{1-\alpha_{i}\left(1+\frac{\beta}{1+\beta}\right)} & \text { for } \alpha_{i}<\frac{1}{1+\frac{\beta}{1+\beta}}, \\ +\infty & \text { otherwise }\end{cases}
$$

which is also lower than the off-net price in equation (3) above. Nevertheless, a strategic motive to increase off-net prices above marginal cost remains, since even if $a=c_{T}$ and $\alpha_{i}=\frac{1}{2}$ the off-net price in equation (11) is higher than $c_{O}+c_{T}$. Moreover, when market shares are asymmetric a "connectivity breakdown" can still occur, ${ }^{35}$ and a large network still has an incentive to create higher on-net/off-net price differentials than a smaller network. The reason is that, even when call externalities are fully internalized, a large network remains more capable of reducing the utility of a smaller network's subscribers, by reducing the number of calls received by each of those subscribers, than vice versa. ${ }^{36}$

An additional effect occurs if individuals in stable calling relationships act so as to minimize the total costs of their communication. Then, ceteris paribus, an increase in network $i$ 's off-net price results in an increase in incoming off-net calls from network $j$, which will tend to increase its profits, whenever $a>c_{T}$, without reducing the utility of network $i$ 's subscribers. This creates an additional motive for implementing high off-net prices when call externalities are internalized by subscribers to different networks who act as a team. Hence, the degree to which the internalization of call externalities, or related call propagation effects, reduce networks' strategic incentives to engage in on-net/off-net price discrimination is an empirical question which is at present far from being resolved.

\footnotetext{
${ }^{34}$ This can be obtained by setting the first-order derivative of network $i$ 's profit with respect to $p_{i j}$ equal to zero (see Jeon et al. 2004, p. 105). Since network $j$ 's subscribers also send more calls to network $i$ when externalities are internalized in this way, profits from interconnection also increase whenever $a>c_{T}$. However, this effect has no influence on the optimal choice of $p_{i j}$ by network $i$.

${ }^{35} \mathrm{By}$ contrast, with symmetric market shares $p_{i j}^{*}=\left(c_{0}+a\right)(1+\beta)$, which remains finite for all finite values of $\beta$.

${ }^{36} \mathrm{We}$ conjecture that this result would also hold in the model of Cambini and Valletti (2007) - i.e. that with asymmetric market shares, a larger network would charge higher off-net prices than a smaller network, even if $x=1$.
} 


\section{3 "Bill-and-Keep" versus "Cost-Based" Ter- mination Charges}

An important issue in the access pricing literature, starting with the seminal work of Armstrong (1998) and Laffont et al. (1998a, b), has been whether reciprocal access pricing agreements can be used as instruments of tacit collusion, and if and how they should be regulated. In particular, several papers have asked if bill-and-keep arrangements, which correspond to zero access charges, can actually be anticompetitive. A natural benchmark against which the welfare effects of such agreements can be evaluated is cost-based access pricing, which sets access charges equal to marginal cost.

The early literature (Laffont et al. 1998a; Armstrong 1998; Carter and Wright 1999) showed that firms can use above-cost access charges as a mechanism to obtain higher profits when they compete in linear retail prices. By coordinating on high enough access charges, monopoly call prices can be achieved, and if inter-network traffic flows are symmetric, firms do not bear any burden from the high charges they pay to each other. ${ }^{37}$ On the basis of these conclusions, Carter and Wright (1999, p. 24) argued that bill-and-keep may be the second-best regulatory policy when the first-best (i.e. marginal cost pricing) is unobtainable.

Subsequent papers have extended the analysis in several directions and have shown that networks may wish to agree on interconnect prices below marginal cost if: $(i)$ networks compete in two-part tariffs with discriminatory prices (Gans and King 2001), or (ii) demand for subscription is elastic (Dessein 2003; Schiff 2002). Gans and King (2001) showed that when the operators can discriminate between on-net and off-net calls, below-cost termination rates can soften downstream price competition, allowing firms to obtain higher profits. Hence bill-and-keep arrangements may be undesirable from the consumer's perspective. ${ }^{38}$ An opposing position was taken by Cam-

\footnotetext{
${ }^{37}$ This collusion result is not robust under more sophisticated pricing strategies, however. Armstrong (1988) and Laffont et al. (1998b) demonstrated that, with two-part retail prices, the access charge has a neutral effect on profits: any possible access profit would simply be passed on to customers via a reduction in their subscription fee.

${ }^{38}$ See also the discussion in Armstrong and Wright (2007). Gans and King (2001) showed that when firms compete in two-part tariffs and discriminatory prices (but without allowing
} 
bini and Valletti. Valletti and Cambini (2005) showed that networks may wish to agree on interconnect prices above marginal cost if ex-ante investments have to be made, in order to weaken competition over investments. Cambini and Valletti (2003) demonstrated that bill-and-keep arrangements may be beneficial due to a positive impact on investments in quality prior to price competition occurring.

All of these papers shared the assumption that only the caller benefits from a call. Until recently the literature lacked a model of CPP systems incorporating nonlinear pricing and price discrimination, as well as call externalities. As noted above, the inclusion of call externalities in the analysis is of particular importance, since this has significant effects on competition, the equilibrium structure of retail prices, and optimal regulatory policy. Indeed, once it is recognized that both parties to a call receive benefits from it, it is surprisingly easy to demonstrate that this profoundly changes the analysis of welfare-optimal prices and termination rates.

DeGraba (2003) In a very simple and general framework, DeGraba (2003) shows that in the presence of call externalities, access prices equal to a network's cost of completing a call is typically inefficient. He considers a model in which the sender of a call obtains a fraction $\lambda$ of the total utility of the call, while the receiver obtains a fraction $(1-\lambda)$ of the total utility. The total per-minute cost of a call is $c=c_{O}+c_{T}$, where, as in Section $2, c_{O}$ is the cost of originating a call, and $c_{T}$ is the cost of terminating a call.

DeGraba (2003) argues that a call can be viewed as a public good jointly consumed by the sender and the receiver, and hence applies the same logic as in a "Lindhal equilibrium." Letting $p_{O}$ be the price charged to the sender and $p_{T}$ the price charged to the receiver, the only prices which result in efficient

for call externalities), both on-net and off-net prices will be set equal to marginal cost, with the latter depending upon the wholesale termination rates. When the firms set termination charges independently (i.e. non-cooperatively), prices are higher than they otherwise would be, and profits and consumer surplus are lower. When firms set termination charges cooperatively, however, the negotiated interconnect charge is less than marginal cost, so each network makes losses on interconnection. This is profitable because it makes attracting marginal subscribers less valuable, and so price competition is muted. The profit-maximizing symmetric termination charge may be greater or less than zero. In the latter case, bill-and-keep may be as close as firms can get to collusive profit maximization. 
consumption and add up to $c$ are

$$
p_{O}=\lambda c \quad \text { and } \quad p_{T}=(1-\lambda) c .
$$

So only in the case $\lambda=1$ - i.e. in the absence of call externalities - should the sender pay for the entire cost of the call. ${ }^{39}$

If regulation or competition forces networks to charge prices equal to marginal cost, then the optimal access charge that the network of the sender of a call should pay to the network of the receiver is equal to

$$
a^{*}=(\lambda-1) c_{O}+\lambda c_{T}
$$

Then the effective cost of a call paid by the sender's network is $c_{O}+a^{*}=\lambda c$, and the effective cost paid by the receiver's network is $c_{T}-a^{*}=(1-\lambda) c$. So the optimal access charge is such that each network pays a fraction of the cost of producing a call equal to the fraction of the value of the call received by its subscribers. The principle is that when both parties benefit from a call, they should bear its cost in proportion to the benefit they receive. Only when $\lambda=1$ is the optimal access charge equal to the termination cost. And the optimal access charge is equal to zero or even negative if, for example, $\lambda \leq \frac{1}{2}$ and $c_{O} \geq c_{T} \cdot{ }^{40}$

On the basis of these results, DeGraba (2003) argues that bill-and-keep, by imposing some of the cost of a call on each network, is more efficient than cost-based termination charges. DeGraba (2003) also notes that, since the optimal access charge does not depend on the number of calls originating on one network as opposed to the other, bill-and-keep is more efficient than cost-based termination charges even when traffic between networks is not in balance, contradicting the widely-held belief that bill-and-keep arrangements are only appropriate when traffic between networks is balanced. Finally, another obvious advantage of bill-and-keep is that it is much simpler to implement for the regulator than cost-based termination charges. ${ }^{41}$

\footnotetext{
${ }^{39}$ Efficient consumption will also be achieved if the sender pays $\lambda c$ and the receiver pays 0 (or indeed any price lower than $(1-\lambda) c$ ), so it is not necessary to introduce charges for receiving calls to induce consumption efficiency. If $p_{T}=0$, the "unrecovered" costs $(1-\lambda) c$ can be recovered via a fixed fee or subscription charges, levied on either party.

${ }^{40} \mathrm{An}$ access charge equal to zero is also efficient when the marginal cost of a call is zero.

${ }^{41}$ Wright (2002b) criticizes this conclusion, arguing that bill-and-keep does not solve "the
} 
Berger (2004, 2005) DeGraba's simple model is not well-suited to analyzing competition between networks. By contrast, Berger (2004) analyzes network competition in linear prices using the standard Hotelling model of Laffont et al. (1998b) in the presence of call externalities. As in the models discussed in Section 2 above, he shows that call externalities have a significant effect on competition because, given the access charge, networks set higher off-net prices to make subscription to the rival networks less attractive. Therefore, on-net prices are lower than off-net prices and, contrary to the results of Gans and King (2001), cooperatively agreed access charges may exceed the welfare-optimal charge, even if the cooperatively agreed charge is below marginal cost.

Building on the model of Jeon et al. (2004), Berger (2005) completes the analysis by considering optimal access charges in the presence of nonlinear (i.e. two-part) tariffs and call externalities. He shows that the welfare maximizing termination rate is always less than marginal cost, and quite possibly less than zero.

This result can be obtained by noting that the efficient off-net price is equal to the equilibrium on-net price and, from equation (4), the welfaremaximizing access charge is equal to

$$
a^{*}=\frac{(1-\beta) c_{T}-2 \beta c_{O}}{(1+\beta)} .
$$

Thus the welfare-maximizing access charge is always less than the total marginal cost of terminating a call $c_{T}$, and for realistic values of $\beta$ frequently negative (e.g. for $c_{O}=c_{T}$ and $\beta>1 / 3$ ). Therefore, in contrast to Gans and King's result, and corroborating the view of Cambini and Valletti (2003), Berger (2005) argues in favor of bill-and-keep, showing that such an arrangement is welfare improving compared to cost-based access pricing.

fundamental problem of pricing out network externalities." Because bill-and-keep excludes a positive termination charge that may serve to internalize the network externality, Wright concludes that it often leads to less efficient outcomes. In response to this, DeGraba (2002) points out that a positive termination charge will typically harm the subscribers of the (e.g. fixed) network, and may consequently reduce the number of subscribers to this network. Hence the net effect on welfare of positive termination charges is at best ambiguous, with both network and call externalities, and must be evaluated empirically. 
Finally, Armstrong and Wright (2007, pp. 20-21) also consider the noncooperative setting of termination rates in the presence of call externalities. Similar to Berger's results, their analysis suggests that, with two-part tariffs and discriminatory prices, cost-based access pricing can never be optimal from the social viewpoint, when the call externality is taken into account. In realistic cases, the optimal access charge is less than zero. It follows that, from the social viewpoint, bill-and-keep - i.e. $a=0$ - is an improvement over cost-based access pricing.

\section{Empirical Evidence}

\subsection{Market Shares and Network Effects}

As mobile networks are highly compatible with each other, the network effects that exist in mobile markets are primarily induced by the network operators themselves, through off-net/on-net call price differentials (these have been described as "tariff-mediated network effects" by Laffont et al. 1998b). With tariff-mediated network effects, other things being equal, consumers will prefer to join the network which has the largest number of their calling partners, and hence large networks are favoured over smaller ones. Some recent empirical work has attempted to estimate the extent to which tariffmediated network effects influence consumer behavior in mobile markets.

Birke and Swann (2006) study mobile network calling patterns and estimate subscription-level network effects using market data from Ofcom and micro-level data on consumers' usage of mobile telephones from the survey Home OnLine. They estimate two classes of models which illustrate the role of network effects. The first is an aggregate model of the comparative volume of on-net and off-net calls which shows that the proportion of off-net calls falls as mobile operators charge a premium for off-net calls.

Figure 1 - taken from Birke and Swann (2006) - shows the actual development of on-net and off-net calls from the beginning of 1999 to the end of 2003. Whereas a roughly equal amount of on-net and off-net calls were made at the beginning of the period, the on-net call volume increased considerably from Q4 1999. For the whole period the percentage of on-net 


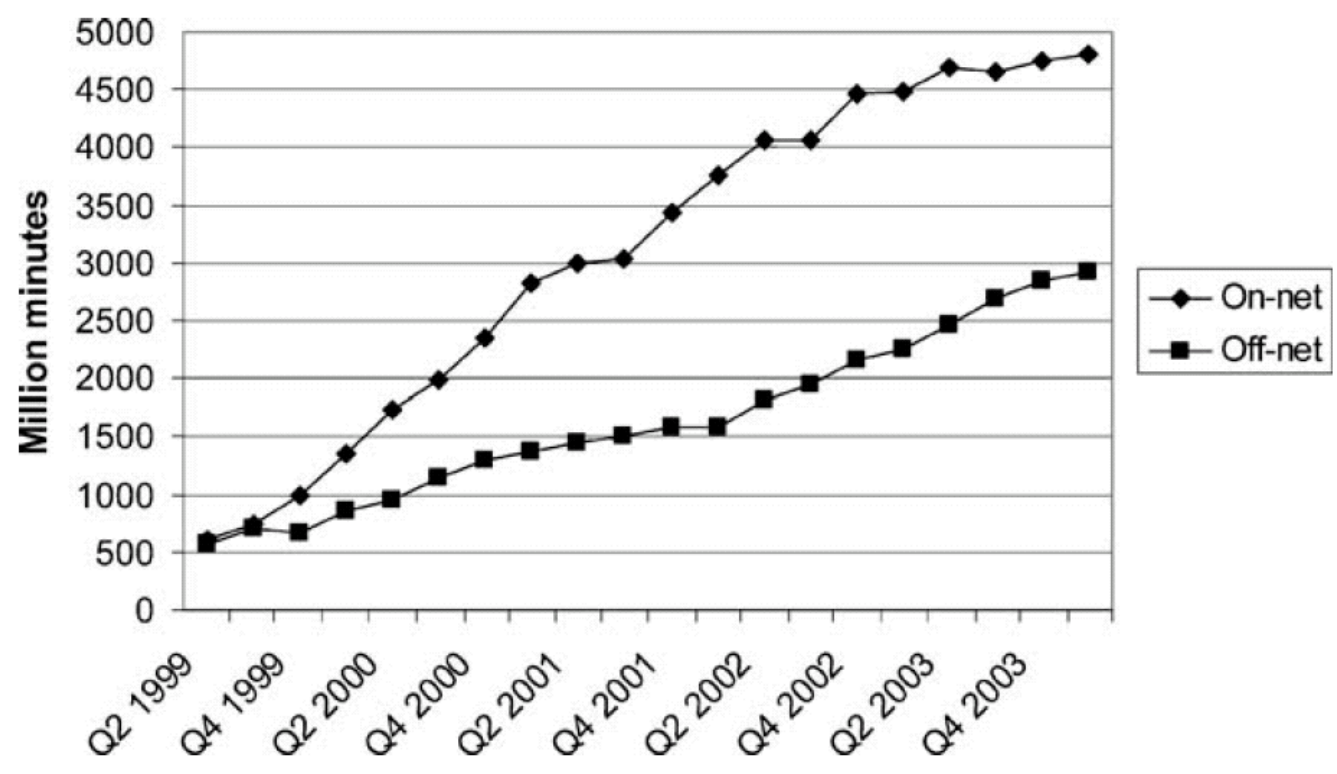

Figure 1: Birke and Swann (2006). Development of on-net and off-net call volumes. Based on data from Ofcom.

calls is above $50 \%$, which is far higher than the expected percentage that Birke and Swann (2006) calculated in the absence of any network effects.

Figure 2 - taken from Birke and Swann (2006) - depicts the development of the ratio between prices for off-net calls and for on-net calls. In early 1999, off-net calls were about twice as expensive as on-net calls (19 ppm compared to $10 \mathrm{ppm}$ ). Two years later, off-net calls were about five times more expensive (26 ppm compared to $6 \mathrm{ppm}$ ). Afterwards, a decrease in the price ratio can be observed, but prices for off-net calls were still about three times higher in early 2004 (16 ppm compared to 5 ppm).

Birke and Swann's estimation results indicate that the observed ratio of off-net to on-net calls is sensitive to the price premium for off-net calls, especially when time lags for consumer inertia and imperfect price information are allowed for. However they also find that, even in the absence of any price discrimination between on-net and off-net calls, a disproportionate number of calls are on-net, suggesting the existence of a "pure" network effect unrelated 


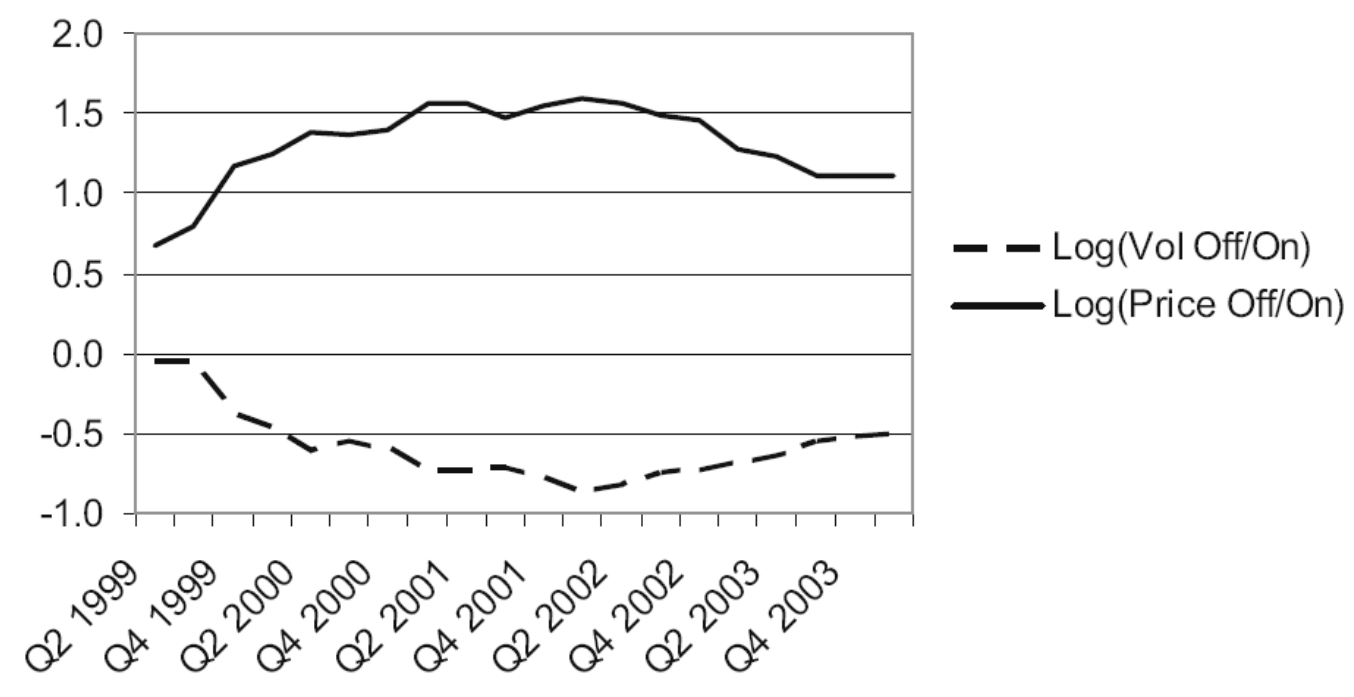

Figure 2: Birke and Swann (2006). Price-ratio between off-net and on-net calls.

to price differentials.

Their second model analyses the choice of operator by individual consumers. They find that individual subscribers' choices show considerable inertia, but are heavily influenced by the choices of the other members of the same household. There is also some evidence that individual choice of operator is influenced by the total number of subscribers for each operator.

Birke and Swann (2006) argue that their results provide a strong indication that network effects play an important role in mobile telecommunications, particularly on usage patterns of mobile phones and on operator choice. They suggest that tariff-mediated network effects lead to the coordination of operator choice, and (Birke and Swann 2006, p. 83):

"the strong reaction from consumers to changes in the price ratio of off- and on-net calls suggest that inducing network effects by operators has been a successful strategy. It can in particular be used by the incumbent operators to fend off challenges by new entrants, such as ' 3 ' in the UK and also by any operator gaining 
a lead over the other operators. [...] High termination charges and high costs for off-net calls have been regarded in a recent ruling by the UK regulator OFCOM as being the result of significant market power that operators have on their individual networks. As our results suggest, the high price of off-net calls cannot only be a result of market power, but can be a significant source of market power, which can especially be used to preempt entry by new competitors. If high switching costs are present in mobile telecommunications, this market power would be highly stable once consumers have aligned their operator choice even after the price differential between on- and off-net calls has been lowered."

In a companion paper, Birke and Swann (2007) directly examine provider choice in mobile networks using class surveys undertaken in the UK, Malaysia, Italy and the Netherlands. The Netherlands differs from the other countries in the study in that its mobile operators do not charge different prices for onnet and off-net calls. They found that the respondents strongly coordinated on their choice of mobile phone operator if operators induced tariff-mediated network effects, but not if prices for off-net calls were the same as prices for on-net calls, suggesting that coordination and network choice strongly depends on tariff-mediated network effects, rather than on other factors. Interestingly, they found that the degree of coordination for H3G subscribers in the UK was insignificant when compared to the larger networks such as Vodafone (Table 6, p. 15). They attribute this to the fact that in 2005, H3G was the only UK mobile operator that did not charge higher prices for off-net calls, but offered packages of calling time regardless of the network to which calls are made. ${ }^{42}$

The Birke-Swann studies therefore provide considerable support for the recent theoretical literature, which suggests the importance of on-net/off-

\footnotetext{
${ }^{42}$ In a related study, Birke and Swann (2005) estimate the importance of tariff-mediated network effects in mobile telephony, and the impact of the structure of social networks on consumers' network adoption decisions, using social network data from a survey of second year undergraduate students at the University of Nottingham Business School. As in their other studies, they find that students strongly coordinate their choice of mobile phone operators, but do this only for operators which charge a price differential between on-net and off-net calls.
} 
net price discrimination in influencing network choice and calling behavior in mobile markets. In particular, that strategically inducing network effects can be a successful strategy for attracting and maintaining market share, and for preempting entry or retarding the growth of smaller networks.

\subsection{International Experience with Bill and Keep}

Only a few countries internationally use bill-and-keep, and it tends to be used selectively. The United States, for example, is "calling party network pays" (CPNP) for calls to fixed incumbent operators, but is effectively bill-and-keep for mobile-to-mobile calls and for calls from one non-incumbent fixed provider to another (or to a mobile operator). In France, bill-and-keep was used for mobile-to-mobile calls until 2004. Hong Kong has bill-and-keep for mobile-tomobile calls whereas mobile networks pay to both send and receive calls from fixed networks. Singapore uses a U.S.-like system, with bill-and-keep for calls terminating on the mobile network, but CPNP for calls terminating on the fixed network. A general conclusion which emerges however, is that bill-andkeep arrangements lead to low retail prices and very high mobile utilization rates compared with CPNP countries, with little effect on penetration rates. Further, with bill-and-keep, incentives for on-net/off-net price discrimination are reduced, and in some cases these disappear altogether. So as claimed above, bill-and-keep arrangements tend to encourage a more efficient retailpricing structure.

On-net/off-net price differentials Large price differentials for on-net and off-net calls are common in most European mobile markets. In the UK, pre-pay packages, to which some $65 \%$ of customers subscribe, frequently discriminate between on-net and off-net calls. ${ }^{43}$ Typically these price dif-

\footnotetext{
${ }^{43}$ A review of operators' websites in September 2007 provides several examples of this. O2's Pay \& Go Talk Anytime tariff offered on-net calls at $25 \mathrm{ppm}$ for the first 3 minutes of a day, and 5 ppm afterwards, compared with an off-net mobile rate of $40 \mathrm{ppm}$. T-Mobile's "Mates Rates" tariff (its default tariff for new customers), offered on-net calls for 8 ppm, compared with an off-net mobile rate of 40 ppm. Orange's "Magic Numbers" scheme offered calls at $15 \mathrm{p}$ per hour (as opposed to the standard rate of $15 \mathrm{ppm}$ ) to 3 nominated on-net numbers. Of the four incumbent operators, only Vodafone failed to discriminate between on-net and off-net calls in its pre-pay tariffs, although as noted below, it did
} 
ferentials are much larger than can be accounted for by mobile-to-mobile termination charges of approximately $6 \mathrm{ppm}$. Discrimination is also apparent in the MNOs' monthly packages. ${ }^{44}$ Ofcom reports that for the UK market as a whole, average charges for off-net calls were 8.9 ppm in 2006, compared with $3.5 \mathrm{ppm}$ for on-net calls, having been as high as $22.6 \mathrm{ppm}$ versus 5.1 ppm in $2002 .{ }^{45}$

Data from European countries such as France, Germany and Spain tell a similar story. France's largest mobile operator, Orange, offers monthly packages with unlimited on-net call allowances. The second largest operator, SFR, offers monthly packages with unlimited call allowances to 3 nominated on-net numbers. ${ }^{46}$ In Germany, some operators' tariffs offer unlimited on-net calls. ${ }^{47}$ And in Spain, the largest mobile operator, Telefonica, offers a prepay tariff which charges $3.3 \mathrm{ppm}$ for on-net calls compared with an off-net call rate of 39.9 ppm. ${ }^{48}$ Other operators also offer on-net call discounts.

By contrast, in countries which have adopted bill-and-keep arrangements between mobile operators, these differentials are reduced, or even absent altogether. In the US and Canada, monthly packages, which are adopted by the majority of customers, ${ }^{49}$ tend to offer a fixed monthly minute allowance for peak off-net calls, and unlimited minute allowances for both on-net and

\footnotetext{
discriminate in some of its monthly packages.

${ }^{44}$ A review of operators' websites in September 2007 again provides examples. O2's more costly Anytime packages offered a fixed minute allowance for peak off-net calls, but an unlimited allowance for on-net calls. Vodafone's Small Business packages offered unlimited allowances for on-net calls to other business numbers. T-Mobile's U-Fix packages offered on-net calls at $10 \mathrm{ppm}$, compared with an off-net mobile rate of $35 \mathrm{ppm}$. Finally, Orange's more costly Canary packages offered a fixed minute allowance for off-net calls but an unlimited allowance for on-net calls.

${ }^{45}$ See Ofcom (2007b), Figure 4.40. Ofcom's estimates of LRIC for the UK operators in 2006 were approximately $5 \mathrm{ppm}$ for Vodafone and O2, and $5.7 \mathrm{ppm}$ for T-Mobile and Orange. So the average price of on-net calls in 2006 was significantly below the estimated values of LRIC.

${ }^{46}$ Sourced from operator websites: 12 September 2007.

${ }^{47}$ Annex to the European Electronic Communications Regulation and Markets 2006, Volume 1, European Commission, 29 March 2007, p. 112.

48 "Solid performance, strong trends," Telefonica, 6 June 2007.

${ }^{49}$ In Q1 2007, only $15 \%$ of customers in the US, and $22 \%$ of customers in Canada, were pre-pay (Global Wireless Matrix 1Q07, Merrill Lynch, 15 June 2007).
} 
off-peak calls. ${ }^{50}$ Pre-pay packages also tend to offer generous or unlimited minute allowances for both on-net and off-peak, off-net calls. ${ }^{51}$

The situation in Hong Kong and Singapore is very different. Pre-pay packages, which are common, ${ }^{52}$ tend not to discriminate at all between onnet and off-net calls. Most monthly packages also tend not to discriminate between on-net and off-net calls. ${ }^{53}$

France provides a particularly interesting example of the possible relationship between wholesale termination arrangements and on-net/off-net price differentials. Mobile termination is currently CPNP, and as noted above differentials are common. However, these differentials have only emerged since $2005,{ }^{54}$ prior to which mobile-to-mobile termination was on a bill-and-keep basis (see Marcus 2007, Section 4.1.2.2).

Prices and usage The price and usage advantages of bill-and-keep over CPNP have been noted by a number of commentators. Marcus (2007) observes that "countries with CPNP systems tend to have higher retail prices and lower use of mobile service than those with Bill and Keep." Littlechild (2006) and Ovum (2006, pp. 78-79) reach similar conclusions. ${ }^{55}$ Ofcom has also recognized the advantages of bill-and-keep, noting that it "tends to yields

\footnotetext{
${ }^{50}$ In some cases minute allowances are literally unlimited, whereas in others they are so generous, relative to the minute allowances for peak off-net calls, that they are effectively unlimited for most customers.

${ }^{51}$ Review of operator websites, August 2007.

${ }^{52}$ In Q1 2007, 66\% of customers in Hong Kong, and 40\% of customers in Singapore, were pre-pay, compared with $66 \%$ of customers in the UK (Global Wireless Matrix 1Q07, Merrill Lynch, 15 June 2007).

${ }^{53}$ Sourced from operator websites: August 2007. Some monthly plans have separate allowances for on-net and off-net calls, but the on-net allowances are far less generous than those seen in the US and Canada.

${ }^{54} 2006$ Annual Report, ARCEP, p. 195, http://www.arcep.fr/index.php?id=1\&L=1.

${ }^{55}$ Littlechild (2006) compares Receiving Party Pays (RPP) countries with Calling Party Pays $(\mathrm{CPP})$ countries, noting that " $R P P$ tends to reduce average revenue per minute and increase average usage without adversely affecting mobile penetration". However, while all of the countries he describes as RPP in this context have bill-and-keep wholesale arrangements, one of them (Singapore) is now CPP, and in two others (US and Canada), customers can opt for CPP tariffs if they wish. Hence Littlechild's conclusion that bill-andkeep "has essentially all the beneficial consequences of RPP (for which it has traditionally been the basis) but offers the prospect of avoiding the downside [i.e. mandatory RPP]".
} 


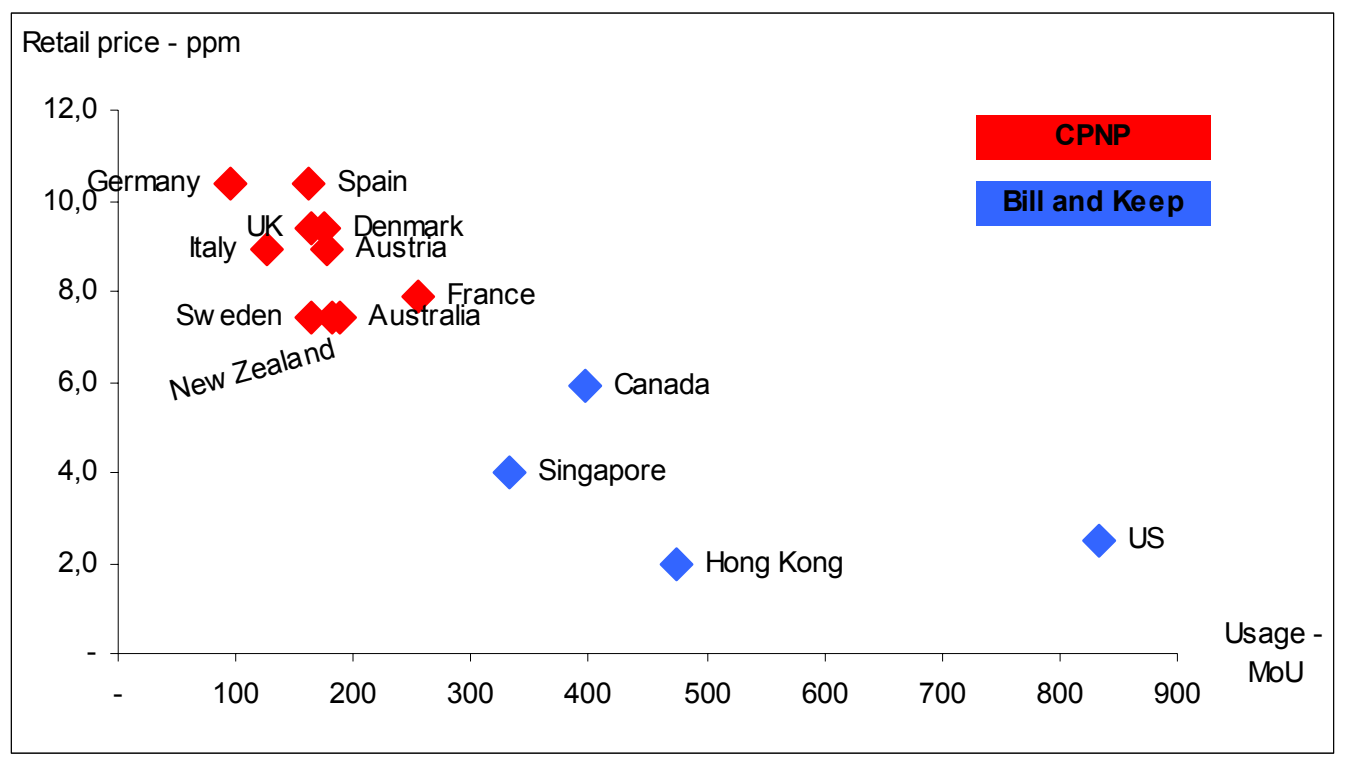

Figure 3: Usage and average retail prices, Q1 2007: bill-and-keep vs CPNP. Source: Merrill Lynch Global Wireless Matrix 1Q07, 15 June 2007.

significantly higher minutes of use per subscriber" and that "average revenue per minute is lower." 56 Figure 3 compares usage and average retail prices between bill-and-keep and CPNP countries.

To summarize, high termination rates tend to lead to high retail prices for originating calls, and correspondingly lower usage rates. As we might expect, the higher marginal prices at the retail level tend to depress call origination due to the price elasticity of demand. It is difficult to avoid the conclusion that, via the effects identified in this paper, bill-and-keep leads to more intense price competition and hence lower prices for mobile subscribers.

\footnotetext{
${ }^{56}$ Paragraph 6.6, Mobile Call Termination - Market Review, Ofcom, 30 March 2006. Ofcom reaches its conclusion by comparing the bill-and-keep countries (USA, Canada, Hong Kong, Singapore and China) with CPNP countries in Europe and elsewhere.
} 


\section{Conclusion}

In an extensive review of the economic arguments and empirical evidence surrounding the "Calling Party Pays" (CPP) versus "Receiving Party Pays" (RPP) debate, Littlechild (2006) has summarized the arguments in favour of bill-and-keep in terms of avoiding the "bottleneck monopoly problem:"

"In many countries there is widespread concern at the level of mobile termination charges. This is attributable to the bottleneck monopoly created by the Calling Party Pays (CPP) principle. It has led to increasingly severe price controls on termination charges. [...] The Receiving Party Pays (RPP) principle, which applies in North America and several Asian countries, avoids the bottleneck monopoly problem. [...] Surprisingly, CPP regulators have either ignored RPP or rejected it for various alleged disadvantages. These do not withstand investigation. However, in CPP countries there is still concern about the idea of paying to receive calls.

There is a way to get the benefits associated with RPP without this disadvantage. RPP is based on a 'bill and keep' regime. Some mobile operators in RPP countries are now offering customers the option of calling plans with free incoming calls. Changing to a 'bill and keep' regime would avoid the bottleneck monopoly and associated distortions of conventional CPP regimes, yet enable operators and customers themselves to choose how to pay for calls - in effect, to choose between CPP and RPP."

As we have argued in this paper, in addition to the advantages noted by Littlechild and others, a move to bill-and-keep also reduces incentives for inefficient on-net/off-net price discrimination, which is at least partly responsible for softening price competition and maintaining higher call charges in the UK and other CPP countries. In addition, by exacerbating MNOs' incentives to introduce socially inefficient tariff structures, high mobile-to-mobile termination charges, which make off-net calls more costly than on-net calls, create an entry barrier for small networks which are unable to profitably replicate incumbents' pricing strategies. 
Some recent related work in a dynamic framework by Cabral (2007a)(2007b) tends to support these conclusions. Cabral (2007a) considers a dynamic model of competition between proprietary networks in which consumers die with a constant hazard rate and are replaced by new consumers. Firms compete for new consumers by offering network entry (i.e. subscription) prices, which may be below cost. In each period consumers enjoy a benefit upon joining a network which is increasing in network size during that period. Cabral studies network pricing decisions and the stationary distribution of market shares, which depends upon the barrier to entry created by "network effects". One source of network effects is the pricing of network services. In the case of mobile telecommunications, to the extent that operators set different on-net and off-net prices, the utility from being connected to a given network will be increasing in the number of other users on the same network.

The equilibrium state in the model is generally asymmetric, since a larger network is always more likely to attract new subscribers than a smaller network. Indeed, for sufficiently strong network effects, the market is characterized by "increasing dominance", (i.e. the larger network increases in size relative to the smaller network), and differences in pricing are thus exclusively driven by "market power considerations" related to capturing new subscribers. Since consumers are willing to pay more to join a larger network, in equilibrium larger firms charge higher network 'entry' prices, i.e. spend less on subsidizing subscription. Cabral (2007a) uses his model to measure the barrier to entry caused by network effects, and to estimate long-run market share asymmetries. ${ }^{57}$

Cabral (2007b) applies this framework to mobile markets, and shows that a positive markup on termination charges, in addition to the short run deadweight loss from inefficient price discrimination, also implies a higher degree of increasing dominance in market share dynamics: that is, a greater tendency for larger networks to become even larger. In addition to leading to a more asymmetric industry structure, steep access charges also increase barriers to entry. Specifically, tariff -mediated network effects decrease the value

\footnotetext{
${ }^{57}$ In one of his simulations, Cabral shows that long-run market shares will converge to $80 \%$ for the larger ("incumbent") network and $20 \%$ for the smaller ("new entrant") network.
} 
of an entrant (or a small network), and increase the average time that it takes for an entrant to achieve a certain given size.

As we have shown in this paper, efficient pricing in mobile networks requires equal on-net and off-net charges which are below marginal cost, to correct for the call externality. Hence, optimal termination charges are also below marginal cost, and the difference between termination charges and marginal costs is likely to be larger for mobile-to-mobile charges than for fixed-to-mobile charges, to compensate for more intense competition between mobile networks. A move to bill-and-keep for mobile-to-mobile termination would likely result in a more efficient wholesale and retail price structure, help to eliminate barriers to entry caused by "tariff-mediated" network effects, and increase welfare and competition in the mobile market.

\section{References}

[1] Ahn, H. and M.-H. Lee (1999) "An Econometric Analysis of Demand for Access to Mobile Telephone Networks," Information Economics and Policy, 11, 297-305.

[2] ANACOM (Autoridade Nacional de Comunicações) (2007) Wholesale Voice Call Termination Markets in Individual Mobile Networks: Price Control Obligation, Lisbon, October.

[3] Andersson, K., O. Foros and F. Steen (2006) "Text and Voice: Complements, Substitutes or Both," CEPR Discussion Paper 5780.

[4] Armstrong, M. (1988) "Network Interconnection in Telecommunications," Economic Journal, 108, 545-564.

[5] Armstrong, M. (2002) "The Theory of Access Pricing and Interconnection," in M. Cave, S. Majumdar and I. Vogelsang (eds.), Handbook of Telecommunications Economics, North-Holland, Amsterdam.

[6] Armstrong, M. and J. Wright (2007) "Mobile Call Termination in the UK," UCL, September.

[7] ARCEP (Autorité de Régulation des Communications Électroniques et des Postes) (2007) Analyse des Marchés Pertinents: Consultation 
Publique Relative à L'analyse du Marché de Gros de la Terminaison D’appel Vocal sur les Réseaux Mobiles en Métropole, Paris, July.

[8] Atiyas, I. and P. Dogan (2006) "When Good Intentions Are Not Enough: Sequential Entry and Competition in the Turkish Mobile Industry," mimeo, Kennedy School of Government, Harvard University.

[9] Berger, U. (2004) "Access Charges in the Presence of Call Externalities," B.E. Journal of Economic Analysis \& Policy, 3(1), Article 21.

[10] Berger, U. (2005) "Bill-and-Keep vs. Cost-Based Access Pricing Revisited," Economics Letters, 86(1), 107-112.

[11] Binmore, K. and D. Harbord (2005) "Bargaining over Fixed-to-Mobile Termination Rates: Countervailing Buyer Power as a Constraint on Monopoly Power," Journal of Competition Law and Economics, 1, 4972 .

[12] Birke, D. and G. M. P. Swann (2005) "Social Networks and Choice of Mobile Phone Operator," mimeo, Nottingham University Business School.

[13] Birke, D. and G. M. P. Swann (2006) "Network Effects and the Choice of Mobile Phone Operator," Journal of Evolutionary Economics, 16(1-2), 65-84.

[14] Birke, D. and G. M. P. Swann (2007) "Network Effects, Network Structure and Consumer Interaction in Mobile Telecommunications in Europe and Asia," mimeo, Nottingham University Business School.

[15] Cabral, L. (2007a) "Dynamic Price Competition with Network Effects," mimeo, New York University, April.

[16] Cabral, L. (2007b) "Competition and Regulation in Wireless Telecommunications: A Dynamic Perspective," mimeo, New York University, November.

[17] Cadima, N. and P. Barros (2000) "The Impact of Mobile Phone Diffusion on Fixed-Link Networks," CEPR Discussion Paper 2598. 
[18] Calzada, J. and T. Valletti (2007) "Network Competition and Entry Deterrence," Economic Journal, forthcoming.

[19] Cambini, C. and T. Valletti (2003) "Network Competition with Price Discrimination: 'Bill and Keep' is Not So Bad After All," Economics Letters, 81, 205-213.

[20] Cambini, C. and T. Valletti (2007) "Information Exchange and Competition in Communications Networks," Journal of Industrial Economics, forthcoming.

[21] Carter, M. and J. Wright (1999) "Interconnection in Network Industries," Review of Industrial Organization, 14(1), 1-25.

[22] Competition Commission (2003) Vodafone, O2, Orange and T-Mobile: Reports on References Under Section 13 of Telecommunications Act 1984 on Charges Made by Vodafone, Orange, O2 and T-Mobile for Terminating Calls Made by Fixed and Mobile Networks, HMSO, London.

[23] De Bijl, P. and M. Peitz (2002) Regulation and Entry Into Telecommunications Markets, Cambridge University Press, Cambridge.

[24] DeGraba, P. (2000) "Bill and Keep at the Central Office as the Efficient Interconnection Regime," OPP Working Paper Series No. 33, December, FCC.

[25] DeGraba, P. (2002) "Bill and Keep as the Efficient Interconnection Regime? A Reply," Review of Network Economics, 1(1), 61-65.

[26] DeGraba, P. (2003) "Efficient Intercarrier Compensation for Competing Networks when Customers Share the Value of a Call," Journal of Economics and Management Strategy, 12, 207-230.

[27] Dessein, W. (2003) "Network Competition in Nonlinear Pricing," RAND Journal of Economics, 34 (4), 593-611.

[28] Gans, J. and S. King (2000a) "Mobile Network Competition, Customer Ignorance, and Fixed-to-Mobile Call Prices," Information Economics $\&$ Policy, 12(4). 
[29] Gans, J. and S. King (2000b) "Using 'Bill and Keep' Interconnect Agreements to Soften Network Competition," Economics Letters, 71(3), 413420.

[30] Gans, J., S. King and J. Wright (2005) "Wireless Communications," in M. Cave, S. Majumdar and I. Vogelsang (eds.), Handbook of Telecommunications Economics, North-Holland, Amsterdam.

[31] Genakos, C. and T. Valletti (2007) "Testing the 'Waterbed' Effect in Mobile Telephony," mimeo, Imperial College.

[32] Gruber, H. and F. Verboven (2001a) "The Evolution of Markets under Entry and Standards Regulation-The Case of Global Mobile Telecommunications," International Journal of Industrial Organization, 19, 1189-1212.

[33] Gruber, H. and F. Verboven (2001b) "The Diffusion of Mobile Telecommunications Services in the European Union," European Economic Review, 45, 577-588.

[34] Hahn, J. (2003) "Nonlinear Pricing of Telecommunications with Call and Network Externalities," International Journal of Industrial Organization, 21, 949-967.

[35] Hoernig, S. (2007) "On-Net and Off-Net Pricing on Asymmetric Telecommunications Networks," Information Economics \& Policy, 19(2), 171-188.

[36] Jeon, D., J.-J. Laffont and J. Tirole (2004) "On the Receiver Pays Principle," RAND Journal of Economics, 35, 85-110.

[37] Laffont, J.-J., P. Rey and J. Tirole (1998a) "Network Competition I: Overview and Nondiscriminatory Pricing," RAND Journal of Economics, 29(1), 1-37.

[38] Laffont, J.-J., P. Rey and J. Tirole (1998b) "Network Competition II: Price Discrimination," RAND Journal of Economics, 29(1), 38-56.

[39] Littlechild, S. (2006) "Mobile Termination Charges: Calling Party Pays versus Receiving Party Pays," Telecommunications Policy, 30(5-6), 242277. 
[40] Marcus J. (2007) Interconnection on an IP-Based NGN Environment, prepared by WIK-Consult, gmbh.

[41] Ofcom (2006) Mobile Call Termination: Proposals for Consultation, Office of Communications, London.

[42] Ofcom (2007a) Mobile Call Termination: Statement, Office of Communications, London.

[43] Ofcom (2007b) The Communications Market 200\%, Office of Communications, London.

[44] Ovum (2006) Review of the Regulatory Framework for Fixed-Mobile Convergence in Hong Kong, April.

[45] Quigley, N. and I. Vogelsang (2003) Interconnection Pricing: Bill and Keep Compared to TSLRIC, Charles River Associates (Asia Pacific) Ltd.

[46] Schiff, A. (2002) "Two-way Interconnection with Partial Consumer Participation," Networks and Spatial Economics, 2, 295-315.

[47] Sung, N. and Y.-H. Lee (2002) "Substitution Between Mobile and Fixed Telephones in Korea," Review of Industrial Organization, 20, 367-374.

[48] Taylor, L. D. (2004) "Customer Demand Analysis," in M. Cave, S. Majumdar and I. Vogelsang (eds.), Handbook of Telecommunications Economics, North-Holland, Amsterdam.

[49] Valletti, T. and C. Cambini (2005) "Investments and Network Competition," RAND Journal of Economics, 36, 446-467.

[50] Valletti, T. and G. Houpis (2005) "Mobile Termination: What is the 'Right' Charge?" Journal of Regulatory Economics, 28(3), 235-258.

[51] Wright, J. (2002a) "Access Pricing under Competition: An Application to Cellular Networks," Journal of Industrial Economics, 50, 289-315.

[52] Wright, J. (2002b) "Bill and Keep as the Efficient Interconnection Regime?" Review of Network Economics, 1(1), 54-60. 